\title{
El migrante homoerótico en El vampiro de la colonia Roma de Luis Zapata.
}

\author{
Estefanía PeÑa Steel \\ Magíster en Literatura Hispanoamérica Contemporánea \\ Universidad Austral de Chile \\ estefania.pena@docentes.uach.cl
}

\begin{abstract}
Resumen
La novela El vampiro de la colonia Roma (1979) del escritor mexicano Luis Zapata, puede ser inscrita dentro de las llamadas literaturas heterogéneas, pues convoca en su escritura aquellas "otras" literaturas que permiten explorar, según Moraña, las voces "no siempre claramente audibles de culturas sometidas o soterradas, a través de las formas peculiares que éstas asumen para representarse". La novela de Zapata, de carácter autobiográfico, nos presenta el trayecto vital de un sujeto migrante que relata a un interlocutor directo las instancias y estancias vividas en el espacio de la homosexualidad marginal. El migrante homoerótico transita en los precarios subsuelos de la gran urbe-Ciudad de México. Allí, el sujeto migrante reactiva su memoria para testimoniar y validar otras "alternativas existenciales", como diría tan lúcidamente Antonio Cornejo Polar.
\end{abstract}

Palabras claves: Luis Zapata, El vampiro de la colonia Roma, homoerotismo, narrativa mexicana.

\begin{abstract}
Abstrac
The novel The vampire of the colony Rome (1979) of the Mexican writer Luis Zapata, it can be inscribed inside the calls heterogeneous literatures, because it summons in their writing those "other" literatures that allow to "not always explore the voices clearly audible of subjected or buried cultures, through the peculiar forms that these assume to be represented (Moraña). The novel of Zapata presents us the vital itinerary
\end{abstract}


of an autobiographical migrant fellow of character that he/she relates a direct speaker the instances and stays lived in the space of the marginal homosexuality. The migrant homoerotic traffics in the precarious undergrounds of the great city- Ciudad de México. There, the migrant subject reactivates his memory to testify and to validate other "existential alternatives", as Antonio Cornejo Polar told us so lucidly.

keywords: Luis Zapata, El vampiro de la colonia Roma, Homoeroticism, Mexican literature.

Recibido: $10 / 2 / 2015$

Aceptado: 26/4/2015

\section{Introducción}

Si entendemos con Cornejo Polar que el lenguaje en las literaturas heterogéneas implica no solo normas linguísticas y usos literarios, sino ante todo "formas de socialización tangenciales, subrepticias y hasta casi imperceptibles en los ámbitos generales de las esferas públicas y privadas" (Cornejo Polar 2003: 147), la novela El vampiro de la colonia Roma (1979) del escritor mexicano Luis Zapata, puede ser inscrita dentro de las llamadas literaturas heterogéneas1, en tanto explora, precisamente, esas voces "no siempre claramente audibles de culturas sometidas o soterradas, a través de las formas peculiares

1 En El vampiro de la colonia Roma existen ciertos elementos interpretativos, más allá de las reflexiones desarrolladas en este artículo, que identifican en gran medida los discursos de las "otras" literaturas, las literaturas heterogéneas.Así, por ejemplo, la intención de oralidad que observamos en la escritura-espacios en blanco que connotan silencios, rescate del habla popular marginal; o el referente extratextual que remite a un espacio real-simbólico-la colonia Roma- en cuyo origen (asentamiento indígena prehispánico "tomado" por una compañía extranjera), se entreteje el dislocamiento histórico y cultural que definió, fragmentó y jerarquizó el territorio al que alude la obra. Es decir, ya el título remite en su significación histórico-espacial a una sociedad constitutivamente atravesada por formas de dominación que han provocado desigualdades y violencia. Esta violencia fundacional que da origen a la heterogeneidad de base (Cornejo Polar), no se queda en un pasado distante sino también, se proyecta hacia la modernidad urbana- desde el remoto Aztacalco, usurpado, a la bullente y caótica modernidad de Ciudad de México- con todas sus jerarquías y marginaciones sociales, autoritarismo(s) político(s) y su despojamiento económico. Lo interesante de esta reflexión histórico-espacial, es el hecho de advertir cómo este espacio "robado" a sus habitantes originarios, aristocratizado y transformado en "colonia" por un reducido grupo de "nobles ciudadanos", se ha convertido por la acción del tiempo, el paso de infinitas interacciones y la intervención de diversos sistemas culturales soterrados; en este caso la cultura homosexual, en un territorio heterogéneo y heterogeneizante, en el que "se cruzan ritmos diversos e interconectados, por los que circulan "relatos singulares, microhistorias ficticias o posibles " (Moraña en 2003: 9).Allí, las construcciones, materiales y culturales aristocráticas del pasado- y todo lo que connotan- se 'reclinan' sobre las más recientes y se dejan penetrar por la acción transformadora del migrante homoerótico. 
que éstas asumen para representarse”, según palabras de Mabel Moraña en el prólogo del paradigmático texto Escribir en el aire de Antonio Cornejo Polar (2003: 10).

En El vampiro de la colonia Roma el referente- impertinente desde el punto de vista homogeneizador de la literatura canónica - remite a una de esas "voces" soterradas y disidentes- el discurso homosexual marginal- a través de un imaginario verbal oralizado que credibiliza y valida-más aún- el mundo al que refiere. Así, la novela nos presenta a un sujeto autobiográfico-ficcional-Adonis García- que relata a un interlocutor directo sus "aventuras, desventuras y sueños"- dice el narrador- "trabajando a veces taloneando casi siempre" (Zapata 2004:15), para subsistir en la bullente y heterogénea Ciudad de México, más específicamente, en la otrora aristocrática Colonia Roma.

Considerando lo anterior, la hipótesis de este trabajo sostiene que el narrador-protagonista de la novela, puede ser considerado como un sujeto migrante, en tanto moviliza-como una "memoria insomne"(Cornejo Polar)- diversas "instancias y estancias" sociales y culturales en su difícil devenir homoeróticoerrancia forzada por la discriminación y el despojo-configurándolo como un agente heterogeneizador en cuya propuesta cultural disidente, yace una alternativa existencial (Cornejo Polar) frente a otras posiciones-sujeto occidentales, unitarias y homogeneizantes. En consecuencia, nos interesa en este trabajo describir las distintas situaciones que configuran a Adonis García, narradorprotagonista en esta novela, como un sujeto migrante homoerótico, que debe transitar por una realidad socioespacial y cultural heterogénea, densa, potente, sostenida en profundas desigualdades y en la que se ponen en contacto y conviven niveles sociales, costumbres y creencias a veces muy opuestas y contradictorias.

\section{Sujeto migrante y espacio}

El concepto de sujeto migrante está asociado a las categorías de heterogeneidad sociocultural y de literaturas heterogéneas propuestas por el crítico y teórico peruano Antonio Cornejo Polar. Como se sabe, uno de los aportes basales de su propuesta radica en el reconocimiento de esas otras tradiciones marginales/marginalizadas, "alternativas existenciales" como dirá Cornejo Polar (2003), que se infiltran en el sistema literario peruano (vale también, para otros sistemas literarios indoamericanos) ya no como meros "temas" y objetos de estudio aislados, sino como ejes fundamentales en la reformulación de la conciencia histórica y social y en el devenir de la literatura indoamericana. Desde allí, Cornejo Polar (1995) reconoce y postula un sujeto bicultural o mul- 
ticultural capaz de situarse en diversas condiciones discursivas, es decir, "en capacidad de entender, usar y reproducir signos de otra cultura a la vez que los signos propios" (1996: 34). El sujeto migrante no solo es heterogéneo sino heterogeneizante, pues en su trayecto acerca registros discursivos y prácticas culturales diferentes y hasta contradictorias. En este sentido, aquellas escrituras que proponen contextos y lenguajes "no oficiales" o "registros discursivos disímiles"- como la "lengua marucha" de Lemebel, por mencionar un ejemplo-, y que no necesariamente se vinculen con instancias de marginación étnica, también pueden ser considerados como productores de escrituras heterogéneas, al presentar realidades y códigos linguiísticos que han sido marginados o invisibilizados por la hegemonía institucional, pero que sin embrago, se levantan y operan como posibilidades expresivas y culturales.

Ahora bien, Raúl Bueno (2004) afirma que el migrante "habla desde dos o más lugares": desde un presente y "un pasado enaltecido por la memoria" (53). De igual forma, en la novela que nos convoca, el sujeto migrante homoerótico- que en términos estilísticos sigue la construcción del personaje picarescohabla desde un presente testimoniante, hoy y aquí, describiendo "las experiencias del ayer y los espacios que se dejaron atrás”, es decir, del ayer y el allá. Así también lo entendía Antonio Cornejo Polar, al definir el acto de migrar como "nostalgiar desde un presente"(...) que es o debería ser pleno de las muchas instancias y estancias que se dejaron allá y entonces, (...) en un tiempo espeso que acumula sin sintetizar las experiencias del ayer y de los espacios que se dejaron atrás y que siguen perturbando con rabia o con ternura." (Cornejo Polar 1995: 103). Las instancias y estancias vividas por el migrante se constituyen en una suerte de territorio intangible al que Cornejo Polar denomina "memoria insomne" (1995:103). Ésta emerge, para el caso del narrador en El vampiro de la colonia Roma, por una "voluntad testimoniante" que busca develar la realidad soterrada de la homosexualidad marginal en los subsuelos de la gran urbe.

Desde este punto de vista, entenderemos el acto de migrar no sólo como el traslado geográfico de un lugar a otro, sino también, como un acto de introspección y memoria que da cuenta de la itinerancia vital del sujeto, en la que se han involucrado todos sus niveles (linguiístico, social, cultural, político, espiritual, genérico-sexual) en la odisea de la sobrevivencia urbana. El migrante homoerótico que presenta Zapata se mueve desde el precario espacio de su realidad concreta, hacia el mundo "ideal" construido en su imaginación. Esa "memoria insomne" que otorga sentido al desarraigo del sujeto migrante, es un memoria ilusoria en Adonis-el narrador personaje-, pues su historia vital, familiar, no es más que el espejismo de una modernidad escurridiza e intangible, 
posible solo en la imaginación "technicolor" de la ficcionalidad "cinelandia". Así lo describe

(...) nos íbamos a ir en barco e íbamos a conocer españa y a la familia se me hacía muy buena onda pus no la madre patria sino más bien otro cotorreo tal vez tenía deseos de sentir calor de hogar ¿no? de sentir que tenía una familia me acuerdo que veía la imagen de mis parientes con mucho afecto aunque no los conocía ni en fotos..." ," me imaginaba que vivían ellos (sus parientes) como toledo muy tranquilos medios serios pero sin un chorro de afecto hacia mí (...) y llevándome a los toros y a las verbenas ¿no? sí no te rías (...) porque uno ve todo eso en las películas y se le queda grabado y cree que así son todas las cosas y las gentes en españa como en una eterna película de rocío durcal ( 21-22).

El migrante homoerótico en la novela de Zapata realiza sus trayectorias siempre en dirección de espacios urbanos2. Entendiendo la migrancia como un proceso vital y no sólo como un traslado geográfico, la ciudad tampoco puede ser comprendida únicamente en sus construcciones físicas sino también, en relación con sus innumerables sistemas culturales que le otorgan multiplicidad de formas y sentidos. De ahí que-siguiendo a Perlongher en su Poética urbana- más que pensar la ciudad, ésta se debe delirar y comprender desde "las tramas sensibles que la urden, las condensaciones instantáneas, los climas, las atmósferas, los sentimientos" (1999: 144). Así también, el narrador en la novela se hace parte de estos "flujos" marginales, que captan la trama sensible de la ciudad:

"por andar todo el tiempo en la calle terminé conociendo la ciudad como la palma de mi mano ¿no? o sea muy mal pero la conocía me iba al centro a ver la gente los discos los vendedores ambulantes todo ino? o me metía en los cines en las mañanas cuando apenas los abrían para asearlos me encantaba meterme a los cines vacíos con todas las luces encendidas y un olor a creolina que a mí me gustaba mucho.... caminaba dentro del cine me subía al escenario me sentaba veía a los señores mientras hacían el aseo y fijate nunca me dijeron nada.........me gustaba mucho estar ahí me sentía diferente me olvidaba de todo..." (25).

Existe una forma, un modo particular en que el migrante homoerótico se relaciona con la ciudad. "Vivir la ciudad es sentirla y en ese sentimiento inventarla”, explica Perlongher (1999: 144). El migrante homoerótico transita los

2 Así también ocurre, como lo aclara el propio Cornejo Polar en Escribir en el aire, con el migrante andino cuya trayectoria forzada se orienta hacia el espacio urbano de la modernidad. En el caso del migrante homoerótico de Zapata, el territorio de desarraigo aunque es físico, es más bien afectivo-emocional, pues es la propia "institución familiar" la que lo condena a la trashumancia. Es lo que ocurre también, en la micronovela Salón de belleza, de Mario Bellatin o en Tengo miedo torero de Pedro Lemebel. 
espacios urbanos como parte de un proceso en el que se ponen en contacto sistemas culturales distintos y contradictorios. El migrante deja la impronta de su diferencia y la postula como un sistema cultural alternativo.

Ahora bien, otro elemento que identifica al sujeto de la novela como un sujeto migrante es, ya lo hemos anticipado, su capacidad para "nostalgiar" (de hecho la novela está estructurada como un relato evocativo testimonial) desde un presente y estratificar sus experiencias de vida, sin pretender fundirlas, sino más bien poniendo el énfasis "en la múltiple diversidad de esos tiempos y de esos espacios y en los valores o defectividades de los unos y los otros" (Cornejo Polar 1995: 104). Al "nostalgiar" el narrador en El vampiro de la colonia Roma estratifica sus experiencias vitales en dos grandes espacios temáticotemporales: aquellos lugares y personas del allá y entonces, que podríamos catalogar de "pre-migrante": su infancia en Matamoros, su padre-un refugiado español cuya existencia siempre fue un enigma para el narrador-protagonista; una madre (divorciada de un "militar estúpido"), siempre ausente, silenciosa y enferma; una época de sueños cuando pensaba que " tendría su coche rojo (...) con cola de pescado (...) como rebelde sin causa”; su estancia en la escuela, la muerte de su madre, la muerte de su padre, el descubrimiento de la sexualidad transgresora. Luego, un segundo período en el que emerge su impulso hacia lo que Perlongher denomina "errancia sexual" (1999: 48), etapa que se sitúa entre sus primeras incursiones en la "zona rosa"- especie de subsuelo social en Ciudad de México en donde los jóvenes marginales ejercen la prostitución- hasta su viaje final, imaginario, en el que paradojalmente, se aleja de la ciudad en una nave espacial y "entonces cerraría los ojos y pediría un deseo que no volviera nunca pero nunca por ningún motivo a este pinche mundo" (223).

Todas sus experiencias vitales forman parte de distintos "estratos", de trayectorias que en la novela se seccionan en "cintas" (estrategia del autor para acentuar la oralidad del discurso)3 o lo que para la literatura canónica serían capítulos. Cada corpus de vivencias se sustenta en la relación espacio-tiempo"vueltas del destino", y cada "volteón del destino" implica un cambio de perspectiva en el narrador: "el destino se me dio un volteón y empezaron a sucederme cosas que no me habían pasado antes" (133). Así, el migrante "siempre es movimiento constante" (Bueno 2004: 55).

A partir de la breve presentación biográfica del narrador podemos identificar una tercera instancia que ciñe la figura del sujeto migrante homoerótico:

3 La "sensación" de oralidad en esta novela está también reflejada en las referencias al trascriptor testimonial, que, al perecer podría ser el propio autor: "si no me hubiera pasado todo lo pasó seguramente estaría en otro lado y tú (el trascriptor) estarías escribiendo otras mamadas" (Zapata 1979:133). 
la situación de precariedad "fundante", emocional y social que sustenta su trayectoria. Nos cuenta el narrador

(...) cuando ya entré a tercero de secundaria la situación en la casa ya era totalmente insoportable (...) mi medio hermano no dejaba de tomar (...) mi cuñada (...) ya me empezaba a ver feo (...) me decía con la mirada que me largara (...) me daba la sopa fría cuando me daba un pedacito de carne que me cabía entre dos muelas".Entonces, dice el narrador-protagonista "me empecé a volver bien vago ya no me gustaba la escuela me aburría enormemente la escuela (56).

Esta precariedad fundante es el motor que pone en tránsito la vida del narrador y su configuración picaresca: un sujeto familiar y socialmente desarticulado, que se mueve en una sociedad marcada por diferencias socioeconómicas, profundamente desiguales e injustas. Su trashumancia es su esperanza y valiéndose su inventiva, logra sobrevivir. Así leemos en la novela de Zapata

un buen día o un mal día quién sabe porque yo pienso que en ese momento cambió mi vida (...) se dio un volteón mi destino le dije aun cuate que tenía y que estaba medio loco (...) vámonos a México a ver si allá la hacemos (...) vámonos a México al carajo con la provincia nos vamos al defe y allá a ver qué onda" y salimos de león (...) con mucha pero mucha confianza puesta en el defe (...) nosotros pensábamos que allá si triunfaríamos que allá si la haríamos" (38).

Como podemos ver, en este fragmento el narrador-protagonista expresa una disposición hacia la aventura y lo desconocido sustentada en la antigua creencia de que allá, en la ciudad, sí se puede salir adelante. En principio, la relación del sujeto con la ciudad está dada por una suerte de ingenua esperanza de revertir la precariedad del presente. Así se advierte en el fragmento antes citado. Una suerte de imantación que lo lleva a moverse hacia ella, incluso cuando sueña, el narrador lo hace ligado a la urbe. Dice "siempre sueño cosas de ciudad” (105). Es más, la figura del migrante homoerótico en El vampiro de la colonia Roma se construye en relación con "lugares" sociales, económicos y culturales inscritos en la complejidad del tejido urbano. Un constante ir y venir del "defe", un "deambuleo" marcado por breves períodos estacionarios en los que el sino, está siempre dándole "volteones" a su vida: "cuando regresé al defe decidí que mi vida tenía que cambia en qué sentido no sé ni tampoco me propuse cambiarla ella solita cambió el destino se me dio un volteón y empezaron a sucederme cosas que no me habían pasado antes" (133).

La actitud que en principio era ingenua hacia la ciudad como territorio de esperanza, va siendo reemplazada por un sentimiento de "deriva" y por una actitud autoreflexiva e irónica, respecto a la forma en que "pensaba", en el 
pasado, la ciudad: "habíamos salido de león sin ningún plan no sé de veras qué era lo que pensábamos hacer de seguro creíamos que íbamos a llegar y nos íbamos a encontrar un cachito de lotería" (Zapata 2004: 45)

El carácter humorístico-irónico marcado con los constantes "je" del protagonista, puede ser entendido como una estrategia que rompe en gran medida con la estructura melodramática inicial, proponiendo de esta forma, una nueva perspectiva de acceso al relato y sobre todo, de percibir y comprender la homosexualidad. Al respecto, el cronista y crítico mexicano Carlos Monsiváis (2002), plantea una interesante hipótesis respecto a la forma en que los medios de difusión social, presentan y esquematizan "la" realidad en los espacios urbanos a partir del melodrama, proyectando la imagen de la ciudad "como el cuerpo atado de la víctima que espera la puñalada" (231). Es decir, los medios-obviamente bajo las lógicas del poder que representan - determinan un "modo" de relacionarse con la ciudad sustentado en la exacerbación melodramática. Esta "mirada" pone el foco en subjetividades imposibilitadas y en espacios cerrados, victimizantes. Por el contrario, el lenguaje de los flujos homoeróticos-si seguimos a Perlongher (1999)- hace frente, "invade" y reorganiza el espacio con estrategias existenciales alternativas. El autor agrega otro dato interesante y es que el melodrama tiene un sustrato cristiano, específicamente en la idea de "cargar con una cruz". En El vampiro de la colonia Roma el protagonista al reírse de sí mismo, se libera de ese esquema que no permite salidas. José Joaquín Blanco en su aguda crónica de la sociedad mexicana de fines de los 70- Ojos que da pánico soñar (1981)-, plantea una lectura similar. Allí, propone desmelodramatizar la homosexualidad lo que de alguna forma, contribuye a desficcionalizar la cruda realidad de las sexualidades alternativas en la vorágine de la urbe (1981: 34).

Los espacios sociales y culturales por los que transita el migrante homoerótico son heterogéneos, transitorios, sus fronteras son permeables. En alguna medida esto permite el movimiento y el accionar del sujeto como un "actante" contradictorio que, no obstante estar siempre sujeto a los "volteones de la vida", tiende a liberarse de la idea melodramática de ser "víctima del destino": "a mí no me tocó destino o si me tocó se me perdió en el camino"(159). El sujeto de la enunciación es, más bien, un sujeto autónomo, cuyo tono expresivo marcado por el recurso del humor, evade la tendencia "telenovelesca" de un destino marcado por la desgracia, en donde el "pecador debe pagar sus culpas".4

4 Vemos que el migrante homoerótico en la novela, carece de ese "sentimiento", especialmente en lo que respecta a su homosexualidad. Su "lectura" no es moral. Así lo aclara al relatar su primera experiencia sexual: "supe por primera vez lo que eran los placeres de la carne (...) lo 
Los espacios en El vampiro de la colonia Roma se constituyen como microterritorialidades que lindan tanto con la pobreza extrema, como con el lujo desbordante. El narrador nos lo advierte al relatarnos su paso por "un hotelucho de cuarta desos que si acaso llegas a ver en las películas de negros tan feos que no te imaginas que pueda existir en la realidad" (47); así como por una mansión donde llega a ser, como el mismo ironiza, una "cenicienta tercermundista".

El sujeto migrante homoerótico se "toma" la ciudad, la invade y funda5 nuevos espacios, que más bien se constituyen en territorios, pues están demarcados por su sexualidad transgresora, marginal

cada rinconcito tenía un encanto muy particular muy sexual era maravilloso podías coger todo el día todos los días (...) había lugares para todas las horas del día (...) si querías ligar en la mañana te ibas a cualquier sanborns y ya ¿ves? ligabas o en el metro en la estación insurgentes o en las tiendas de discos también como de nueve a doce y media se ligaba mucho en los baños del puerto Liverpool o en los baños ecuador o en otros baños (201).

El migrante homoerótico conoce en y con su desplazamiento. La sexualidad heterogeneizante del migrante homoerótico imagina y asume la ciudad como una "totalidad intuitiva" (Perlongher 1999: 144). En su acontecer acentúa las diferencias y pone en contacto distintos niveles socioeconómicos y culturales: "me acuerdo en especial de los (baños) ecuador que eran son increíbles porque es totalmente otra onda ahí ves señores que no más van a que les den su piquete (...) hasta albañiles y carpinteros y demás que se van a distraer de sus obligaciones (201). Así también, "en aquella época nomás la ciudad me fascinaba (...) parecía como si se acabara de descubrir la homosexualidad todo el mundo andaba en ese rollo (...) veías de todo- dice el narrador- artistas famosos políticos renombrados intelectuales pintores músicos de todo ino?"(208). De esta forma, al desplazarse de un universo socioespacial y cultural a otro, el migrante homoerótico "pone en acción, hace evidente y aun genera distintas heterogeneidades" (Bueno 2004: 55).

En estos espacios tomados en y con las diferencias del migrante homoerótico, se originan códigos que la creatividad del deseo y la sobrevivencia logran articular como sistemas de comunicación alternativos, en el complejo laberinto de la cultura urbana. Pensemos, por ejemplo, en los baños del sanborns del án-

chistoso es que después no me sentí culpable (...) la homosexualidad es una cosa de lo más normal (...) como pienso ahorita que cada uno tiene derecho a hacer con su vida sexual lo que se le pegue la gana” (31-52).

5 Todas acciones que- según Cornejo Polar y Bueno- identifican al migrante. 
gel, lugar de encuentro donde el narrador contacta y a veces, ejerce la prostitución. Allí, el narrador "descubre" e implementa un sistema de "agujeritos" que en principio servía para espiar y luego, para comunicarse con posibles clientes:

...me fui al sanborns de madero y entons ahí (...) hice un agujerito diminuto y ahí quedó (...) quince días después regresé y ya vi mi agujerito un poco más grandecito y luego como un mes después me encuentro a un cuate y me dice (...) " qué buenos están los agujeros (en el sanborns)" y fui y había un boquete gigantesco que habían tenido que tapar con una madera y luego ya del otro lado habían hecho otro agujero o sea ya eran tres los que se comunicaban ino? tres cuates por eso digo que son muy buena onda porque favorecen la comunicación (206).

El migrante homoerótico que presenta la novela es un sujeto linguísticamente heterogéneo, en tanto apela a la oralidad del discurso marginal homosexual. Asimismo, es un sujeto preformativo, pues al fundar y re-territorializar espacios con sus propios sistemas de comunicación, sus actos adquieren trascendencia grupal. Así “(...) cuerpo, actitud acciones, lengua, creencias, costumbres y otros signos se filtran por entre los esfuerzos que hace el migrante para ser funcional en la cultura que ahora lo enmarca" (Bueno 2004: 56). Por lo tanto, en El vampiro de la colonia Roma los espacios migrantes no sólo son entendidos como construcciones arquitectónicas, sino también como proyectos territoriales y culturales disidentes, que nos enseñan a "pensar la cultura antes y más allá" de la homogeneizante idea de "nación".

\section{Impulso de fuga}

“(...) era como una corriente que me arrastraba sin que yo me diera cuenta" (Zapata 1979:125)

El migrante homoerótico que moviliza la novela de Zapata, está ceñido por ciertas fuerzas intensivas y formas expresivas que lo incitan y conducen en busca de "lo nuevo":

... en aquella época decía "bueno" a cualquier cosa cualquier cosa nueva me parecía mejor que otra como que siempre tenía la necesidad de estar cambiando constantemente y hasta la fecha ives? mira por ejemplo yo no puedo coger más de tres veces con el mismo cuate al cabo de dos o tres cogidas su cuerpo me empalaga me aburre me parece como si llevara quince años viviendo con él siempre tengo la necesidad de estar viendo nuevas pingas nuevas nalgas nuevo todo ino? claro a veces los conservo como amigos pero eso ya es otra cosa porque luego me puede interesar lo que hacen lo que piensan ¿ves? (Zapata 1979:61). 
¿Cómo interpretar esa imperiosa necesidad de "lo nuevo" presente en el fragmento anterior? En su estudio Avatares de los muchachos de la noche Perlongher aclara que "en la base de toda práctica de la prostitución, a veces triste pero siempre dinámica, hay un impulso de fuga” (1999: 50). Fuga de la familia, de la "ley de la pareja legítima y procreadora" (Foucault 2002:9); del trabajo, de toda responsabilidad institucional, del placer rutinario, de los afectos rutinarios, de los esquemas y modelos que en el migrante homoerótico, no forman parte de su subjetividad trasgresora y transitoria. Su ley es siempre, la ley de los cuerpos que sólo es posible en "los brillos opacos del margen", como afirma Perlongher (1999.45). En el laberinto urbano el narrador-protagonista experimenta su libertad inherente: “...en realidad hago lo que quiero y cuando quiero- dice el narrador- y eso ps yo creo que eso es la felicidad ino? hacer lo que quieras hacer y cuando lo quieras hacer..." (217-217). Este impulso de fuga-suerte de "pulsión migrante"6 que mueve al personaje- tiene su anclaje en una historia personal marcada por profundas precariedades y miserias (económica, emocional), que sitúan a Adonis, el narrador-personaje, en un sistema social perverso y deshumanizado. Sobre esta base, el sujeto es desterritorializado de su espacio y lo impulsa hacia un tránsito radical: el deambuleo hacia la prostitución homosexual.

El sujeto migrante homoerótico se configura en la novela como un sujeto descentrado, contradictorio, inestable, "pero" constructivo, estratégico y abierto. Un sujeto que reconoce en la base de su trashumancia la esencia de una soledad mayor. Por ello es que es un sujeto con menos "arraigo colectivo" (Cornejo Polar), pues de esta forma no depende de nadie para seguir su impulso migrante: "como que me daba cuenta de que siempre iba a estar solo y de que por más que trates siempre está solo podrás tener compañía por un rato por un tiempo o por siempre ¿no? pero por dentro toda la vida vas a estar solo" (101). Por lo mismo, las relaciones interpersonales están ceñidas por la fugacidad, la transitoriedad y la desmelodramatización: "aunque alguien te quiera pues no se va a morir por ti" (101)

El migrante disuelve la noción coherente, unitaria y homogénea del sujeto occidentalizado (Bueno 2004:37). Pensemos a modo de ejemplo, en el momento en que, por uno de esos "volteones" del destino, Adonis García se transforma en "protegido" de Zabaleta, un acaudalado diplomático. En esa

6 Parafraseo la "pulsión nómade" a la que hace referencia Perlongher en su ensayo Avatares de los muchachos de la noche (siguiendo a Deleuze y Guattari). La diferencia entre uno y otroaclaran los autores en Mil mesetas- radica en que el migrante va de un punto a otro, al igual que el nómade, pero el migrante lo hace "sin importar si ese punto es dudoso, imprevisto o mal localizado" (2004: 385) Es decir, la trayectoria del migrante es imprevisible, se mueve por una suerte de pulsión instintiva. 
oportunidad, cuenta el narrador, tenía todo lo que un sujeto "socialmente coherente" pudiera desear. Zabaleta lo "disfraza" con un elegante smoking para que se haga pasar por un refinado personaje francés: "el vampiro de la colonia roma había muero por un día había dejado colgada mi chamarra y mis jeans (...) y me había convertido en todo un señor", dice el narrador (123). Zabaleta le propuso cambiar su vida, "debes pensar en tu futuro (...) porque no puedes creer que toda tu vida vas a vivir de esto (el "taloneo" o prostitución) (...) así es que -continúa el narrador- ahí me tienes instalado como rey en la mansión de los seiscientos sótanos y ochocientas escaleras con la vida futura planeada y solucionada (...) pero aburriéndome como una ostra (123). Entonces surge el impulso de fuga y contra toda "lógica" se pregunta:

¿y por qué no salir al sanborns aunque sea a ver (...) como ligan (...) no me podía hacer ningún mal ir nomás de visita y ahí te voy al sanborns del ángel (...) con la más honesta de las intenciones pero ya estando allí me empezó a entrar no sé que como nostalgia o como ganas así desas que no puedes controlar de chichifear (...) de saber que yo podía valerme por mí mismo por mis propios medios (...) era como una corriente que me arrastraba sin que yo me diera cuenta (125).

La autoironía que asume el narrador en relación a su posición genéricosexual, es también una manera de cuestionar al sujeto hegemónico. Queda de manifiesto en las referencias constantes del narrador al mundo del cine, es decir, un mundo en donde el sujeto es parte de una realidad aparente y en donde la hegemonía hollywoodense impone sus cánones heterodominantes y estético-ideológicos. El narrador contrasta su propia identidad con la del sujeto definido, perfecto, héroe patrio, promovido como ideal masculino por el celuloide estadounidense y al cual él, alguna vez aspiró:"también pensaba que iba a ser supermán-dice el narrador- si en serio pero eso cuando estaba chico ¿a poco tú nunca lo pensaste? y acabé siendo esperman je”7 (Zapata 1979:25). Es decir, la identidad del migrante homosexual no solo pone en jaque el "modelo" genérico hegemónico, sino también la imagen política-ideológica de un sujeto-sistema capitalista, que impone un orden espacial, precario, vulnerable, injusto. Dice el narrador: "me gustaba mucho estar ahí (en el cine) me sentía diferente me olvidaba de todo me sentía padre (...) veía muchísimas películas todo lo que me ponían en frente". Sin embargo, "las únicas que no me gustaban eran las de amor esas sí no las soportaba (...) lo que más me molestaba era el momento (...) se besan el muchacho y la muchacha" (26) O sea, aquellas imágenes del "amor manido", institucionalizado, en las que sólo se representa el amor heterosexual.

7 Remitiéndonos a las características picarescas de la novela, he aquí, en la figura del antihéroe “espermán”, un contrapunto al ideal “caballeresco supermán”, propio de la cultura hegemónica. 
De igual forma, el espacio narrativo que nos presenta Zapata apela a subjetividades homosexuales. Es decir, desinstala la idea de "la" homosexualidad como una identidad fija y limitada, discusión que queda de manifiesto en la diferenciación que el propio narrador establece entre la "loca" y el "homosexual no travestido"8. El siguiente fragmento da cuenta de esta posición

las locas son las que nos desprestigian a los homosexuales de corazón a los homosexuales serios je a los que no tenemos que andar gritando a los cuatro vientos que somos putos" (48).Y más adelante, encontramos: “(...) poco a poco coral se fue volviendo más loca empezó a exagerar más sus ademanes sus poses a volverse cada vez más afeminado hasta que un día se ha de haber dado cuenta de que a él no le interesaba ser homosexual (...) sino mujer porque es diferente ino? (209).

La figura del migrante homoerótico que nos entrega Luis Zapata, se infiltra por tanto, en esas "azarosas zonas de alianzas, contactos y contaminaciones", al decir de Cornejo Polar (2003:11), relevando memorias subalternizadas que el discurso moderno-occidental no ha podido "archivar" y que pese a su violentado transcurrir por la Historia, resisten, perviven y se transforman en nuevas enunciaciones.

\section{Referencias bibliograficas}

BUENO CHÁVEZ, Raúl (2004) Antonio Cornejo Polar y los avatares de la cultura. Lima: Latinoamericana editores.

BLANCO, J. J. (1981) "Ojos que da pánico soñar" en Función de medianoche: Ensayos de literatura cotidiana. México: Ed. Era.

CORNEJO POLAR Antonio (2003) Escribir en el aire. Ensayo sobre la heterogeneidad cultural en las literaturas andinas. Lima-Berkeley: Centro de estudios literarios "Antonio Cornejo Polar" (CELAP) - Latinoamericana Editores.

CORNEJO POLAR Antonio (1995) "Condición migrante e intertextualidad multicultural: el caso de Arguedas" en Revista de Crítica Literaria Latinoamericana 42; pp.101-109

DELEUZE, Gilles y GUATTARI, Félix (2004) “Tratado de nomadología” en Mil mesetas. Valencia: Editorial Pre-textos.

ECHAVARREN, Roberto (1997) La muerte del hombre y de la mujer en Arte andrógino: estilo versus moda en un siglo corto. Montevideo: Ed. de Brecha.

FOUCAULT, Michel (2002) Historia de la sexualidad. La voluntad de saber. Buenos Aires: Siglo XXI.

8 Al respecto, Roberto Echavarren (1997) sostiene una interesante reflexión en su artículo La muerte del hombre y de la mujer. Allí, discute y reconoce dos formas de expresión homosexual: la superhembras y los supermachos, estos se constituyen como polos de los géneros dejando entre ambas una gama de variantes que se adscriben a la cultura gay (58-81). 
FOUCAULT, Michel (1999) "Espacios diferentes” en Estética, ética y hermenéutica. Barcelona: Paidos; pp.431-441.

MORAÑA, Mabel (2003) "Prólogo" en Antonio Cornejo Polar Escribir en el aire. Lima: Latinoamericana Editores.

MONSIVÁIS, Carlos (2000) "Ciudadanía y violencia urbana: pesadillas al aire libre" en Ciudadanías del miedo. Susana Rotker (edit.) Caracas, Nueva Sociedad.

PERLONGHER, Néstor (1999) Prosas Plebeyas. Buenos Aires: Ed. Colihue.

ZAPATA, Luis (1979) El vampiro de la colonia Roma. México: Editorial Grijalbo, S.A. 